\title{
Correspondence
}

Letters for publication in the Correspondence columns should not ordinarily be more than 500 words and should be addressed to: The Editor, British Journal of Psychiatry, 17 Belgrave Square, London SW1X 8PG

\section{WHAT BRAND OF TRICYCLIC DO YOU PRESCRIBE?}

Dear Sir,

The spreading legalization of the substitution of generic for brand name drugs, including psychotropics, is responsible for an escalating number of patients being given by dispensing pharmacists a generic instead of a prescribed brand name product. In the case of tricyclic antidepressants this practice can be hazardous because, as the Food and Drug Administration has stated (Federal Register, Vol. 43, No. 34-February 17, 1978), 'available data suggest that the various marketed brands of the same oral tricyclic antidepressant may not have comparable therapeutic effects' (due to bioequivalence differences), and 'the substitution of a poorly bioavailable form in the regimen of a patient controlled on a fully available form would result in reversion to the depressed state'.

I am gathering instances of: (1) depressed patients who did not respond to initial treatment with a generic tricyclic antidepressant but did respond to a subsequently administered brand name tricyclic antidepressant; or (2) depressed patients who responded to a brand name tricyclic and relapsed when a generic form was substituted. I would be grateful if my fellow psychiatrists who have had patients adversely affected by treatment with a generic tricyclic antidepressant would share their data with me.

\section{West Lake Avenue,} Baltimore, Maryland 21210,

U.S.A.

$$
\text { Frank J. Ayd, Jr. }
$$

\section{CLASSIFICATION INTUITION OR STATISTICS?}

\section{DeAR Sir}

Garside and Roth (Joumal, July 1978, 133, 53-67) diagnose psychiatry as intuitive genius confirmed by questionable multivariate statistics. They seem anxious to reassure us that with some developments in statistics we can hope for much greater objectivity.

One fears, however, that their views could make less informed research workers too rigid about the groups compared, and therapists inflexible; further idiographic approaches by either may be undervalued. Classifying objectively by intuition and/or multivariate statistics may be demonstrably impossible. This is really a central intellectual debate between nominalists, conceptualists and realists. The difficulty may not be because our statistical logic is incomplete. Ours could be epistemological difficulties about objectivity. The relation between knower and known could be involved. The 'truth' of our classes depends on their value for various purposes and people.

One is doomed in psychiatry in part to choose one's language, way of acting and believing, and one is necessarily parochial even in intention. Surely there is a considerable need to emphasize the inevitable, though often defensible, projection involved.

This is not to propose that psychiatrists should adopt a thoroughgoing nominalism, believing things have no more in common than their names. That too is a complex position and demonstrably untenable. It is merely to emphasize that the ontological status of abstract entities, like mental diseases, is beyond our ken. As long as the outcome of our treatments remains complicatedly related to our categories, and multivariate statistics only respond to and act on our own prior assumptions and language, we have difficulties we seem likely to have to continue to tolerate.

Middlewood Hospital,

F. A. JenNer

P.O. Box 134, Sheffield S6 1TP

\section{VALIDITY OF THE ZUNG SELF-RATING} SCALE

DEAR SiR,

In their article on the validity of Zung Self-Rating Depression Scale (Journal, April 1978; 132, 381), Drs Biggs, Wylie, and Ziegler presented some data of their own and made some comments about our previous examination of the Zung scale (1). It seems to me that their report is misleading on both issues.

To hoist the authors by their own petard, they are handicapped by (an) isolated view of psycho- 
pathology' since they obtained their results on a group of outpatient depressives, yet they press on us their general conclusion that the Zung scale is a valid and sensitive measure of clinical severity in depressed patients'. This conclusion is much more general than their data really allow, since their study begins only in the middle range of severity and works downwards from there. All that their results really show is that depressed outpatients can generally recognize when they are feeling somewhat better and a lot better than at the beginning of treatment, and that their selfrating judgments generally agree with two kinds of physician ratings (Hamilton rating and global rating). I don't personally think that is enough to justify their strongly worded conclusion about the continued use of the Zung scale as a research instrument. It would depend very much on what the research question happened to be.

In their discussion of our critical report on the Zung scale, the authors have been, to say the least, less than gracious. In our earlier report (1973) we did not say 'that the ZSDS was not a valid research instrument'. What we said, in effect, was that the Zung scale 'is not recommended for use in research studies' and we were quite specific about the sort of studies we had in mind-those which call for matched groups of depressed patients, such as antidepressant drug trials. We also questioned its empirical utility in psychiatric clinics and suicide prevention centres, since our own results indicated that the Zung scale cannot discriminate mildly depressed outpatients from severely depressed inpatients. The figure in the paper by Dr Biggs and associates indicates exactly the same thing - a Zung score of about 52 can be associated with a Hamilton score of anywhere between 9 and about 32! Dr Biggs and his associates may be encouraged by such results, but I am not.

The authors also make much of the point that the correlations between various depression scales are strongly related to the range of severity studied. They have failed to recognize that we had precisely this point in mind in studying a wider range of clinical severity in our own report, and they neglect to mention that in our paper we specifically discussed the common finding that correlations are always better looking when the scores are toward the low range.

Before we proceed to the statistical analysis of the concurrent validity of the Zung scale, it seems to me that we should first settle the question of its face validity. As we said five years ago, 'the least that can be asked of a rating scale is that it should distinguish mildly depressed individuals from those with an illness of psychotic proportions'. Our own results indicated that the Zung scale cannot do this, and in the absence of evidence to the contrary I will continue to recommend that the Zung scale should not be used in research studies.

The University of Michigan, Mental Health Research Institute, Ann Arbor, Michigan 48109

\section{Reference}

Garroll, B. J., Firlding, J. M. \& Blashki, T. G. (1973) Depression rating scales: a critical review. Archives of General Psychiatry, 28, 361-6.

\section{SUICIDE IN SUDAN}

Dear Sir,

We wish to report a study of 100 cases of suicide and attempted suicide in Khartoum Province, Sudan, during the period 1 June 1971 to 31 May 1975. It included all cases reported to the police of this Province. The reports were screened for age, sex, social status (including marital and economic position) and mental illness, including alcoholism and socio-economic stresses.

Ten were consummated suicides ( 5 men, 5 women). Ninety made serious but non-fatal attempts $(50$ women). The calculated incidence rates for the population of 1.2 million are: 1 in 500,000 for consummated suicide and 1 in 50,000 for attempted suicide.

The commonest age group for both attempted and committed suicide was 10-29 and about half were married. Forty-eight were unemployed, 42 employed and 10 students. Ninety-two were Moslems and 8 nonMoslems. Socio-economic stresses and family problems seemed the commonest causes. Mental illness including alcoholism was less important. The commonest method for suicide was burning.

TABLE

Methods used in suicide

\begin{tabular}{lcc}
\hline \multicolumn{1}{c}{ Method } & $\begin{array}{c}\text { Attempted } \\
\text { suicide } \\
\mathrm{n}=90\end{array}$ & $\begin{array}{c}\text { Committed } \\
\text { suicide } \\
\mathrm{n}=10\end{array}$ \\
\hline Burning & $46 \%$ & $60 \%$ \\
Drugs & $19 \%$ & $10 \%$ \\
Sharp instruments & $14 \%$ & $-10 \%$ \\
Drowning & $9 \%$ & - \\
Kerosene ingestion & $4 \%$ & $10 \%$ \\
Iodine & - & $10 \%$ \\
Alcohol & $-4 \%$ & - \\
Hanging & $3 \%$ & - \\
Jumping from high places & $1 \%$ & - \\
Under cars & & \\
\hline
\end{tabular}

